\title{
Effects of Leadership on Student Success through the Balanced Leadership Framework
}

\author{
Munevver Cetin ${ }^{1}$, F. Sehkar F. Kinik ${ }^{2, *}$ \\ ${ }^{1}$ Faculty of Education, Marmara University, Turkey \\ ${ }^{2}$ School of Foreign Languages, Istanbul Technical University, Turkey
}

Copyright $\mathrm{O} 2016$ by authors, all rights reserved. Authors agree that this article remains permanently open access under the terms of the Creative Commons Attribution License 4.0 International License

\begin{abstract}
Attempts have been made to identify behavior patterns peculiar to leadership by many institutions and organizations; also numerous studies have been conducted in this area. Of all these organizations, The Interstate School Leaders Licensure Consortium (ISLLC) identifies the definitive standards of school leadership. Examining these standards in detail, Mid-continent Research for Education and Learning (McREL) has developed new behavior patterns and focuses on student success related to school leadership; accordingly, in 1998 the Balanced Leadership Framework was suggested as a new leadership approach. In accordance with this framework, to know what to do is not generally considered sufficient to transform classes and schools. It is also significantly important for leaders to know why some actions are necessary, when they need to be applied, and how to apply them in classes and schools skillfully. Hence, the Balanced Leadership Framework has been developed to specify school leaders' own leadership behaviors and to benefit from the research aiming to establish effective school leaders. Thereby, McREL, after the meta-analysis, identifies 21 leadership responsibilities. In this study, after reviewing the literature, a qualitative analysis related to the 8 leadership responsibilities (Culture, Ideals and Beliefs, Communication, Visibility, Input, Relationships, Situational Awareness, Affirmation) that are necessary to form the Purposeful Community has been made. 15 teachers have been asked how leadership responsibilities affect student success and the results are discussed in this study. As a result, the effects of these 8 leadership responsibilities on student success have been clarified explicitly.
\end{abstract}

Keywords Balanced Leadership, Leadership Responsibilities, Student Success, Purposeful Community

\section{Introduction}

Scholars doing research on management frequently focus on the area of leadership. There have been more than 3000 studies based on experiments [1]. The scope of these studies indicates the significance of the concept "leadership" [2]. Thanks to the studies applied so far, new styles of leadership have been put forward; moreover, different approaches to leadership have been constituted.

Educators and policy makers have launched many helpful initiatives to redefine the role of formal school leaders; moreover, numerous studies have been conducted in this field. In 1996, The Interstate School Leaders Licensure Consortium (ISLLC), one of the most important organizations, established common standards for school leaders [3]. After analyzing all the standards indicated by ISLLC, Mid-continent Research for Education and Learning (McREL)[4] focused on student success, developed new behavioral patterns for school leaders and came up with a new leadership approach in 1998 [5]: Balanced Leadership.

\subsection{Balanced Leadership Framework}

School leaders today are faced with multiple calls for change, improvement, and reform. These calls take many forms based on the value preferences of the organization, think tank, or legislator [6]. The belief that leadership and management are important permeates the literature of school effectiveness, especially with relation to schools in special measures, where new leaders are expected to transform the prospects of previously doomed staff and students [7]. Therefore, this belief makes the concept of "school leadership" a much more complicated process. Due to this complexity, the need for balancing the values both inside and outside the organization with student success in direct proportion comes up explicitly while school leaders are managing the educational system in schools.

Nearly 30 years ago, the pioneers of "effective schools" research found out that certain school, classroom, and leadership practices are critically important to student success and school productivity. Researchers correlated effective schools with high expectations for student learning, monitoring of student progress, establishing a safe climate, emphasizing basic skill acquisition, and strong instructional leadership [8]. 
More than three decades of research on the effects of instruction and schooling on student achievement are creating a new science of education. In 1998, McREL (Mid-continent Research for Education and Learning) began synthesizing this growing body of research through meta-analyses of research on student characteristics and teacher and school practices associated with school effectiveness, which has resulted in a new leadership framework [9]. This framework on the literature of leadership is clearly aimed to move beyond abstraction to concrete responsibilities, practices, knowledge and strategies that school leaders need to be effective. After all, by means of the studies on "effective schools" conducted by McREL and meta-analyses, what can be applied in schools in order to enhance student success is put forward through the balanced leadership framework [10].

According to McREL, effective leadership means more than simply knowing what to do as well as knowing when, how, and why to do it [9]. Hence, with the help of the balanced leadership framework, it will guide school leaders on how to put vision stated by organizations into action. Conducting three major quantitative studies aiming to measure the effect of leadership on student success, McREL examined more than 5000 studies and made a meta-analysis which has the following results [10]:

1. No longer is there a question about the effect of leadership on student achievement. Clearly, leadership makes a difference.

2. 21 leadership responsibilities were identified with statistically significant correlations to student achievement and 66 practices or behaviors for fulfilling these responsibilities.

3. The differential impact of leadership emerged as a new phenomenon.

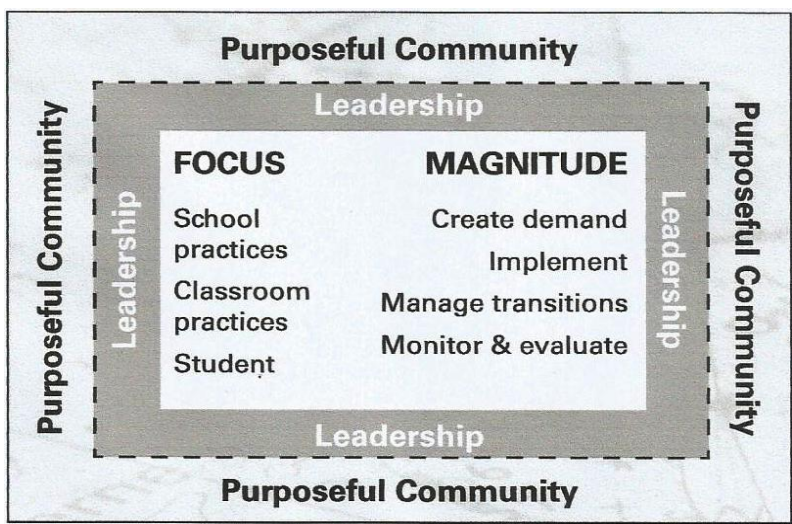

Exhibit 1. McREL's Balanced Leadership Framework

McREL developed the Balanced Leadership Framework so as to make these 21 leadership responsibilities and 66 practices more practical and explained the process below [10]:

"We also wanted to connect our research findings to existing research-based knowledge on change management, diffusion theory, collective efficacy, institutional theory, living systems theory, community development, asset utilization, and school improvement. The result of this effort is the Balanced Leadership Framework (see Exhibit 1), which groups the 21 responsibilities into an organizing structure: leadership, focus, magnitude of change, and purposeful community."

Leadership is unquestionably determined as the fundamental component in the framework because it is the indicative as well as influential factor for forming both purposeful community and effective school-classroom practices. In the basis of this study, only the component "purposeful community" is explained in terms of leadership responsibilities and a qualitative data collection design is applied to a group of teachers.

\subsubsection{Purposeful Community}

After reviewing hundreds of studies on school improvement, it has been concluded that virtually everything in a school occurs within the context of a community, composed of students, parents, teachers and other school staff members, central office administrators and support personnel, the school board, other social agencies, and businesses. The more this diverse community is able to coalesce around shared purposes, the more sustainable and effective a school's change efforts will be. One of the key components of the Balanced Leadership framework, "Purposeful Community" is defined as one with the collective efficacy and capability to use all available assets to accomplish purposes and produce outcomes that matter to all community members through agreed-upon processes (see Exhibit 2) [9].

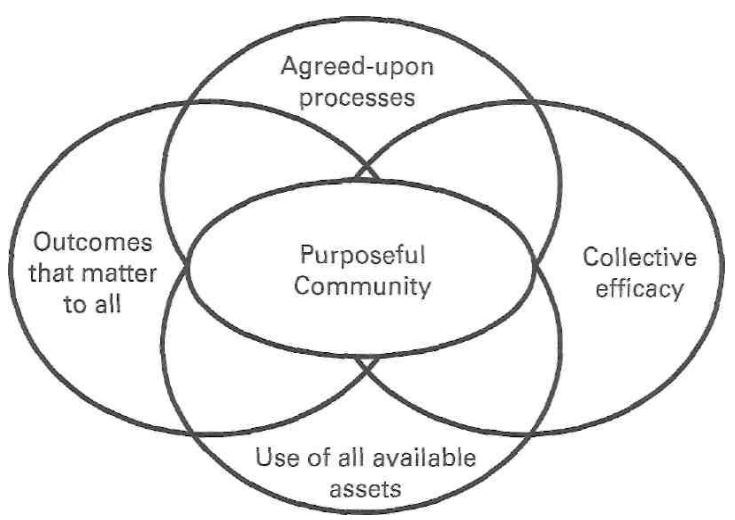

Exhibit 2. McREL's Definition of Purposeful Community

Therefore, school leaders must reorganize the system around agreed-upon processes and outcomes that focus on improvement efforts and inform ongoing improvement. In contrast, given the frequency of changes, schools have had very little success with sustained improvement efforts. Though schools do engage in change, they typically do not enjoy long-term success. Much of this change-without-improvement paradigm can be attributed to a lack of capacity to first create and then work within a purposeful community to accomplish agreed-upon outcomes (see Exhibit 2) [11]. 
In conclusion, purposeful community is the result of leadership growing in that community. Having developed 21 leadership responsibilities in correlation with student success, McREL suggested that 8 of these responsibilities need to be emphasized in order to create a purposeful community in schools. In Exhibit 3, McREL identified specific and measurable indicators explaining these 8 responsibilities [10].

Communities created by political or policy decisions always start as accidental. The nature of how they are created or designated makes them accidental. Members of these communities do not have a common understanding of what they can only accomplish because they are a community. They do not have agreed-upon ways of working together. They do not share knowledge of their tangible and intangible assets. They have not developed collective efficacy. They can, however, be developed into "Purposeful Communities" through strong and effective leadership. For this to happen, principals must understand the value and attributes of Purposeful Community, and emphasize leadership responsibilities in ways that contribute to this development. Without Purposeful Community, it is difficult to imagine schools successfully implementing and sustaining the changes necessary to prepare all of their students to live and work in an increasingly competitive, fast-paced global economy. Within a Purposeful Community, it is difficult to imagine anything else [10].

These responsibilities are the basic components of creating a purposeful community in schools. Hence, the purpose of this study is to analyze qualitatively the effect of school leaders' leadership responsibilities required to develop purposeful communities in schools on student success with the help of teachers' perceptions.

Exhibit 3. Leadership responsibilities to create purposeful community

\begin{tabular}{|c|c|}
\hline Leadership responsibilities & Characteristics of purposeful communities \\
\hline $\begin{array}{l}\text { Culture: fosters shared beliefs and a sense of } \\
\text { community and cooperation } \\
\text { Ideals and beliefs: communicates and } \\
\text { operates from strong ideals and beliefs about } \\
\text { schooling }\end{array}$ & $\begin{array}{l}\text { There is consensus on reasons for working together - general agreement exists on } \\
\text { why the community exists, what can only be accomplished because the members } \\
\text { of the community are together as a community, and that they can accomplish what } \\
\text { is important to them. The principal promotes cooperation, a sense of well-being, } \\
\text { and cohesion among the staff. There is a shared understanding of purpose and a } \\
\text { vision of what the school could be like. The principal holds and shares strong } \\
\text { beliefs about teaching, learning, and the capability of the community to } \\
\text { accomplish specific outcomes. The principal demonstrates behaviors that are } \\
\text { consistent with his or her espoused beliefs. }\end{array}$ \\
\hline $\begin{array}{l}\text { Communication: establishes strong lines of } \\
\text { communication with teachers and among } \\
\text { students } \\
\text { Visibility: has quality contact and } \\
\text { interactions with teachers and students }\end{array}$ & $\begin{array}{l}\text { There are critical connections among key members of the community - the } \\
\text { principal is easily accessible to teachers, other staff, students, and community } \\
\text { members. The principal uses systematic and frequent visits to classrooms, within } \\
\text { the school, and in the community, to reinforce the importance of learning and the } \\
\text { community's capability of accomplishing outcomes that matter. }\end{array}$ \\
\hline $\begin{array}{l}\text { Relationships: demonstrates an awareness of } \\
\text { the personal aspects of teachers and staff } \\
\text { Situational awareness: is aware of the details } \\
\text { and undercurrents in the running of the } \\
\text { school and uses this information to address } \\
\text { current and potential problems }\end{array}$ & $\begin{array}{l}\text { Consensus is developed on ways of working together. The "ways of working" } \\
\text { reflect the "agreed-upon processes" that characterize purposeful communities. } \\
\text { These agreements are a product of the human and personal connections created by } \\
\text { remaining aware of personal needs, staying informed about significant issues in } \\
\text { the lives of community members, and acknowledging significant events in the } \\
\text { lives of community members. These connections allow the principal to stay } \\
\text { informed about relationships among groups and issues that might not surface on } \\
\text { their own. These connections contribute to the ability of the principal to predict } \\
\text { what could go wrong from day to day. }\end{array}$ \\
\hline $\begin{array}{l}\text { Affirmation: recognizes and celebrates } \\
\text { school accomplishments and acknowledges } \\
\text { failures. }\end{array}$ & $\begin{array}{l}\text { Attention is given to building on strengths in addition to addressing weaknesses - } \\
\text { most communities focus on weaknesses or needs. Productive communities (and } \\
\text { organizations) balance their attention on needs or weaknesses with a focus on } \\
\text { community strengths and the importance of playing to them. These strengths are } \\
\text { among the community's most important assets. The principal systematically and } \\
\text { fairly recognizes and celebrates accomplishments of teachers, staff, and students. } \\
\text { The principal is also willing to acknowledge failures along with successes. } \\
\text { Failures are viewed as learning opportunities. The principal reinforces and builds } \\
\text { on the individual strengths of all community members. }\end{array}$ \\
\hline
\end{tabular}




\section{Methodology}

In this part, research design, study group, data collection tool, data collection, and data analysis of this study will be explained in detail.

\subsection{Research Design}

The research design of this study is specified as qualitative data collection gathered in order to find out teachers' perception of school leaders' leadership responsibilities considered necessary for developing the purposeful community.

\subsection{Study Group}

The study group of this study has been selected from private and state, primary and secondary school teachers from different fields of study in the 2013-2014 Academic Year. Purposeful conventional sampling is used to specify the participants.

\subsection{Data Collection Tool}

In this study, a questionnaire form including 6 open-ended questions is used to collect teachers' opinions about leadership responsibilities for developing purposeful community in their own schools. These questions are prepared to determine McREL's 8 leadership responsibilities: Culture, Ideals and Beliefs, Communication, Visibility, Input, Relationships, Situational Awareness, Affirmation. There are 6 questions in the questionnaire because the responsibilities of Communication \&Visibility and Relationships \& Situational Awareness are put together as in the original version (see Exhibit 3).

\subsection{Data Collection}

With the questionnaire put into its final form, it is applied to 15 teachers at the proper place and time specified before.

\subsection{Data Analysis}

So as to analyze the data obtained from the teachers, content analysis is used. The answers to the questions are analyzed by the researchers. Each participant is given a representative code (1-15). During the content analysis, themes specified before according to leadership responsibilities for purposeful community and codes are used in an interpretive way. Details about themes, codes, frequency and number of participants are discussed in the finding and comments section below.

\section{Findings and Comments}

Analyzing all the data gathered from the teachers is the theme of this qualitative study. The data, as previously stated, relates to culture, ideals and beliefs, communication and visibility, input, relationships and situational awareness, affirmation. The codes obtained from content analysis are demonstrated in Exhibit 4 with the themes, frequency (F) and number of participants $(\mathrm{N})$.

Exhibit 4. Distribution of themes and codes

\begin{tabular}{|c|c|c|c|}
\hline Themes & Codes & F & N \\
\hline \multirow{3}{*}{ Culture } & Differences & 4 & 3 \\
& Consensus & 4 & 4 \\
& Teacher & 3 & 3 \\
& Abstract Concepts & 4 & 4 \\
\hline \multirow{2}{*}{ Ideals and Beliefs } & Sharing ideas & 4 & 4 \\
& Lack of participation & 6 & 6 \\
\hline Communication and & Favorable communication & 4 & 4 \\
Visibility & Unfavorable communication & 7 & 6 \\
\hline \multirow{2}{*}{ Input } & Cooperation & 11 & 11 \\
& Autocracy & 3 & 3 \\
\hline Relationships and & Awareness & 10 & 10 \\
Situational Awareness & Lack of awareness & 2 & 2 \\
\hline \multirow{2}{*}{ Affirmation } & Positive affirmation & 2 & 2 \\
& Negative affirmation & 4 & 4 \\
& Both positive and negative & 6 & 6 \\
\hline
\end{tabular}

\subsection{Culture}

Under the theme "culture", four different codes that are differences, consensus, teacher, abstract concepts are examined from the answers of the teachers.

\subsubsection{Differences}

There are 3 participants expressing their opinions 4 times under this code. Some of the participants' views of "differences" are given below:

"In the school I work for, there are great differences between the school administration and the teachers, as well as among the teachers in terms of general educational policy, vision, curriculum, and materials required to be used in classes" (2)

"In my school, the principal's ideas are perceived as the most important decisions. As he is not an open-minded administrator, he does not tolerate differences in the learning environments. He is dominant as a school leader even if there are objections to his decisions." (3)

\subsubsection{Consensus}

There are 4 teachers expressing their opinions 4 times under this code. Some outstanding views are presented below:

"As for educational policy, in my school, there is a great consensus between the school administration and the teachers. That is to say, you can easily observe the positive effects of consensus developed in the school on student success." (14) 
"In my organization, there is a positive atmosphere in terms of cooperation and collaboration. This influences the teachers in a good way as well as the students creating a friendly environment in the school." (15)

\subsubsection{Teacher}

There are 3 teachers sharing their ideas 3 times under this code. Two of the teachers explaining their view of "teacher" are as follows:

"In my school, there is no consensus among the teachers and the principal, which causes an adverse effect on student achievement. That's why, the selection of teacher gains importance as the experienced teacher is believed to manage instructional process much better rather than the school administration." (1)

"The teachers in my school are working cooperatively, which affects the student progress positively." (11)

\subsubsection{Abstract Concepts}

There are 4 participants expressing their opinions 4 times under this code. Some prominent views are given below:

"In my school, the teachers do not want to apply the practices they do not believe but forced by the principal. This leads to a negative atmosphere in the school as well as in the classes; accordingly, the level of teacher motivation lowers and alienation occurs among the teachers." (4)

"Our principal's behaviors and attitudes are quite welcoming for all the staff in the school, which encourages my engagement to my school." (11)

"The general atmosphere of my school is positively reflected to the level of student motivation and trust." (12)

\subsection{Ideals and Beliefs}

Under the theme "ideals and beliefs", two different codes, which are "sharing ideas" and "lack of participation" are detected from the answers of the teachers.

\subsubsection{Sharing ideas}

There are 4 teachers expressing their opinions 4 times under this code. Some outstanding views are below:

"The teachers of my school can easily and willingly share their opinions with the school administration. There are discussions about how we can achieve more success and what we can do more to do our best." (4)

"Our principal encourages sharing ideas through the regular meetings. This is believed to be the best way to improve the students' learning skills in classes." (14)

\subsubsection{Lack of participation}

There are 6 teachers sharing their ideas 6 times under this code. Some of the teachers explaining their view of "lack of participation" are as follows:

"As our principal is the only one who makes decisions without asking our opinions, there is no exchange of ideas." (3)

"I cannot talk about participation of the teachers in the decision making process. There is nothing discussed and planned about the future of my school." (6)

\subsection{Communication and Visibility}

Under the theme "communication and visibility", two different codes that are favorable communication and unfavorable communication are specified from the answers of the teachers.

\subsubsection{Favorable communication}

There are 4 teachers expressing their opinions 4 times under this code. Some outstanding views are presented below:

"The style of communication in my school is quite valuable and constructive, which affects student success directly in a positive way." (7)

"In my school, our school leader has sincere attitudes towards the teachers, which increases the level our motivation a lot. Therefore, we feel better in our classes and I believe that the students feel it." (8)

\subsubsection{Unfavorable communication}

There are 6 teachers expressing their opinions 7 times under this code. Some of the teachers express his/her view below:

"In my school, the principal has a disconnected communication style. There are conflicts between the school administration and the teachers, which lead students to lose motivation to study harder; therefore, the success level of students remains unchanged." (9)

"Because of the communication style our principal has, neither the teachers nor the students are positively affected; accordingly, the level of student success gets low. " (10)

\subsection{Input}

Under the theme "input", two different codes that are cooperation and autocracy are found out from the answers of the teachers.

\subsubsection{Cooperation}

There are 11 teachers sharing their ideas 11 times under this code. Some teachers explained their views of "cooperation" like that: 
"While making important decisions, the principal of my school cooperates with the teachers. He asks our opinions one by one especially about our students' issues related to their achievement." (1)

"The school leader involves the teachers in decision-making process, which creates a positive learning environment in our organization. ” (7)

"Student success is based on teacher motivation which is provided by the cooperation of the teachers with the principal." (11)

"In my school, there is a high level of cooperation that makes our opinions much more important for the school. Interactive communication helps students increase their success." (15)

\subsubsection{Autocracy}

There are 3 teachers sharing their ideas 3 times under this code. One of the teachers expressed his/her ideas below:

"Our principal makes important decisions in an autocratic way. Even if he asks for the teachers' opinions, he makes the final decision. This approach causes students not to improve themselves." (9)

\subsection{Relationships and Situational Awareness}

Under the theme "relationships and situational awareness", two different codes, which are awareness and lack of awareness, are investigated through the answers of the teachers.

\subsubsection{Awareness}

There are 10 teachers expressing their opinions 10 times under this code. Some views are presented below:

"We are informed about the self-improvement activities in our school and our development directly influences our students.” (2)

"All the announcements about the meetings, seminars, or some practical issues are regularly made in our school." (11)

"In my school, teachers are very often encouraged to attend meetings, workshops, and in-school-activities; moreover, in order to increase awareness, there are announcements and reminders made specifically for the teachers." (14)

\subsubsection{Lack of awareness}

There are 2 teachers expressing their opinions 2 times under this code. One of the teachers expresses his/her view below:

"Our principal has no effort to increase the level of teacher awareness. Also, he has no attempt to improve teachers' teachings skills but for the compulsory workshops arranged by the Ministry of Education two times of an academic year." (3)

\subsection{Affirmation}

Under the theme "relationships and situational awareness", three different codes, which are positive affirmation, negative affirmation, and both positive and negative affirmation, can be seen from the answers of the teachers.

\subsubsection{Positive affirmation}

There are 2 teachers expressing their opinions 2 times under this code. One of the participants' views of "positive affirmation" is given below:

"In my school, our principal uses different styles of awarding to positive affirmation.” (11)

\subsubsection{Negative affirmation}

There are 4 teachers expressing their opinions 4 times under this code. Some teachers express their views below:

"If there is a negative situation occurred in the school, the principal will look for the 'guilty' and directly reflect it to the teachers." (8)

"Our school is administered like a company, so the negative feedback got by the students and parents is shared with the teachers as soon as possible, which makes me feel anxious and uneasy." (12)

3.6.3. Both positive and negative affirmation

There are 6 teachers expressing their opinions 6 times under this code. Some views are presented below:

"Our principal is aware of both positive and negative affirmation. For the positive events, he uses awarding system in the school. Also for negative situations, he is very constructive and tries to manage negativities in an encouraging way." (1)

"In our school, there is a fair system including both appreciation and warning even though there are some cases that our principal judges unfairly." (15)

\section{Conclusion, Discussion and Suggestions}

For decades, educators have realized that school leaders are all responsible for student learning as well as student success. Therefore, the concept of leadership directly related to community gains utmost importance [11]. The principal should be characterized to take ultimate responsibility for success or failure of the organization [12]. Taking responsibility, principals need to create a purposeful community in order to achieve success in their schools.

Purposeful Community is one of the three components associated with McREL's Balanced Leadership Framework and acting as the primary mediator for change. A purposeful 
community goes beyond traditional modes of thinking about school improvement; its inclusion in McREL's framework suggests that understanding the role of community and common purpose is critical for sustainable school improvement. School leaders must reorganize the system around agreed-upon processes and outcomes that focus improvement efforts and inform ongoing improvement. In contrast, given the frequency of changes, schools have had very little success with sustained improvement efforts [10]. The 8 leadership responsibilities- Culture, Ideals and Beliefs, Communication, Visibility, Input, Relationships, Situational Awareness, Affirmation - specified in McREL's framework can be defined as the key factors for creating a purposeful community in schools.

In McREL's framework, culture, as a characteristic of a purposeful community, is related to the extent to which the principal fosters beliefs and a sense of community and cooperation. There is consensus on reasons for working together [10]. A general agreement exists on why the community comes together and what they can accomplish as a group together [9]. In this study, under the theme "culture", the code "consensus" has been identified (4/15); as a result, all the codes based on the theme "culture" demonstrate the effect of culture on student success.

Another leadership responsibility, ideals and beliefs, is concerned with the extent to which the principal communicates and operates from strong ideals and beliefs about schooling [10]. There is a shared understanding of purpose and a vision of what the school could be. The principal holds and shares strong beliefs about teaching, learning, and the capability of the community to accomplish specific outcomes [9]. This study has revealed two important codes under the theme "ideals and beliefs". The code "sharing ideas", especially, has indicated the significance of beliefs in a community (4/15) because the code "lack of participation" has clearly shown a negative effect of leadership on student success (6/15).

As for communication and visibility, these responsibilities are considered together as originally classified in the McREL's framework. Communication is about the extent to which the principal establishes strong lines of communication with teachers, staff and among students. Moreover, visibility is connected with the extent to which the principal has quality contact and interactions with teachers, staff and students [10]. There are critical connections among key members of the community. The principal is easily accessible to teachers, other staff, students, and community members [9]. In this study, the theme "communication and visibility" has resulted in two opposite codes: "favorable $(4 / 15)$ and unfavorable communication (6/15)". From these codes, it is concluded that the more effective communication there is, the more successful students there are.

The other leadership responsibility, input, is related to the extent to which the principal involves teachers and staff in the design and implementation of important decisions and policies. Leadership is a shared responsibility and is widely distributed throughout the community [10]. In this research, under this theme, the study has identified two significant codes: "cooperation" (11/15) and "autocracy" (3/15) which can be evaluated as significant findings of the study. As a result of these codes, it is understood that student success will definitely increase if the principal asks for teachers' opinions and communicates indeed with them interactively.

Relationships and situational awareness, another leadership responsibility, are combined together as in the original framework. Relationships can explain the extent to which the principal demonstrates an awareness of the personal aspects of working with teachers and staff. Situational awareness is concerned with the extent to which the principal is aware of the details and undercurrents in the running of the school and uses this information to address problems [10]. Leadership is widely shared throughout the community. Rather than being seen as a position and defined only through positional authority, leadership becomes everyone's responsibility and all community members have opportunities to lead [9]. In this study, under the theme "relationships and situational awareness", the codes "awareness" (10/15) and "lack of awareness" (2/15) have revealed the fact that student success is accomplished much more easily as teachers' level of awareness increases comparatively.

Affirmation, as the last characteristic of a purposeful community, is about the extent to which the principal recognizes and celebrates school accomplishments and acknowledges failures. Attention is given to building on strengths in addition to addressing weaknesses [10]. Productive communities and organizations balance their attention to needs or weaknesses with a focus on community strengths and the importance of playing to them. These strengths are among the community's most important assets [9]. In this research, from this point of view, affirmation has been specified as a significant theme with the help of these three codes: "positive affirmation" (2/15), "negative affirmation" (4/15), and "both positive and negative affirmation" (6/15). In this research, it is clearly concluded that student success will be achieved at a high level if the effective school leader, in terms of purposeful community, celebrates school accomplishments and acknowledges failures.

In conclusion, within McREL' Balanced Leadership Framework, purposeful community can be recognized as one of the most important components. School leaders need to create a purposeful community in their schools if they want to achieve student success indeed. The study shows that the suggestions below would allow leaders to develop purposeful community:

- Principals should create such an atmosphere encouraging cooperation and sharing beliefs within the sense of community.

- Strong ideals and beliefs should be set in the vision of the organization with the help of interactive communication.

- Being visible in the school, principals should be 
easily communicated with by teachers and the other staff.

- During the decision-making process, all the components of the organization should be taken into consideration and full participation of teachers should be encouraged so that they can feel their opinions are valued.

- A consensus based on sincerity should be developed in schools; thus, principals should have knowledge of the teachers and staff that goes beyond their merely professional qualifications.

- Situational awareness should be raised in terms of the details and undercurrents in the running of the school, so as to prevent potential problems in advance.

- Building on strengths and addressing weaknesses should be focused on in the community, and also recognition of school accomplishments and failures should be provided fairly.

\section{REFERENCES}

[1] Celik, Vehbi. (2007). Educational Leadership. $4^{\text {th }}$ Ed. Ankara: PegemA Publishing.

[2] Aydin, Mustafa. (2005). Management of Education. $7^{\text {th }}$ Ed. Ankara: Hatipoglu Publishing.

[3] The Interstate School Leaders Licensure Consortium Standards for School Leaders (ISLLC) [Electronic version]. (1996). Washington, D.C.: Council of Chief State School Officers, 1-7. Retrieved from http://regulations.delaware.gov /AdminCode/title14/ 1500/1590.shtml

[4] McREL (Mid-continent Research for Education and Learning) [Electronic version]. (2008, April). Retrieved from http://www.mcrel.org.html

[5] Waters, T. \& Grubb, S. (2004). The Leadership We Need [Electronic version]. McREL, 1-19. Retrieved from
http://regulations.delaware.gov/AdminCode/title14/1500/159 0. shtml

[6] Schoen, L. \& Fusarelli, L. D. (2008). Innovation, NCLB, and the Fear Factor: The Challenge of Leading 21st-Century School in an Era of Accountability [Electronic version]. Educational Policy, 22/1, 181-203. http://epx.sagepub.com/c gi/content/refs/ 22/1/181.html

[7] Barker, B. (2001). Do Leaders Matter? [Electronic version]. Educational Review, 53/1, 65-76. Retrieved from http://www.tandfonline.com/doi/pdf/10. 1080/00 13191012 00336 64.html

[8] Waters, T., Marzano, R., \& McNulty, B. (2008). McREL's Balanced Leadership Framework: Developing the Science of Educational Leadership [Electronic version]. Retrieved from www.nga.org/cda/files/0404mcrel.pdf.html

[9] Waters, T., Marzano, R., \& McNulty, B. (2003). Balanced Leadership: What 30 Years of Research Tells Us About the Effect of Leadership on Student Achievement (A Working Paper) [Electronic version]. Retrieved from www.mcrel.org/ PDF/LeadershipOrganizationDevelopment/5031RR Balance dLeadership.pdf.html

[10] Waters, T. \& Cameron G. (2007). The Balanced Leadership Framework: Connecting Vision with Action [Electronic version]. Retrieved from http://www.mcrel.org/ product/290.html

[11] Bailey, J., Cameron, G., Cortez-Ford, E. (2004, September). Helping School Leaders Develop the Capacity Necessary for Continuous Improvement: McREL's Balanced Leadership Framework [Electronic version]. McREL Regional Educational Laboratory. Retrieved from www.eric.ed.gov/E RICWebPortal/recordDetail?accno=ED484547.html

[12] Lambert, L. (2002, May). Beyond Instructional Leadership [Electronic version]. Educational Leadership, 59/1, 37-40. Retrieved from http://www.ascd.org/publications/educational -leadership/may02/ vol59/num08/A-Framework-for-SharedLeadership.aspx

[13] Lashway, L. (2002, July). Developing Instructional Leaders [Electronic version]. Eric Digest 160. Retrieved from https://scholarsbank.uoregon.edu/xmlui/bitstream/ handle/1794 /3383/digest160.pdf? sequence $=1 . h t m l$ 